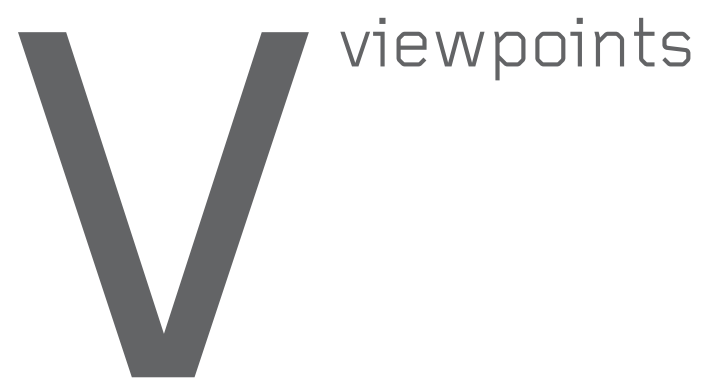

\title{
Viewpoint
}

Beyond Viral

The proliferation of social media usage

has not resulted in significant social change.

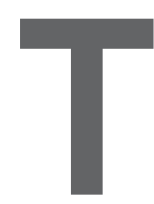

HE GOLDEN AGE of social media coincides with a worldwide leadership crisis, manifested by our seeming inability to address any major global issue in recent years. ${ }^{32}$ These days, no one-be they a charismatic leader or a nameless crowd-seems to be able to make issues popular for long enough to mobilize society into action. As a result of this leadership vacuum, social progress of all sorts seems to have become stymied and frozen. How can this happen precisely in a time when social media, praised as the ultimate tool to raise collective awareness and mobilize society, has reached maturity and widespread use? Here, we argue the coexistence of social media technologies with 'The End of Power'18 is anything but a coincidence, presenting the first techno-social paradox of the $21^{\text {st }}$ century.

In recentyears, we have witnessed social media playing a major role in social mobilization events of historic proportions, such as the Arab Spring, the Occupy Wall Street movement, Ukraine's Euromaidan, and the chaos generated by the England Riots and Boston Marathon bombing manhunt. There has been substantial emphasis on the role of digital social media platforms, particularly Facebook and Twitter, as the facilitators of these mobilizations. Data availability has made it possible, for the first time, to observe the evolution of these events in detail. ${ }^{10,11,13,33}$ Analysis of these events makes it clear that political activists find it difficult to use social media to create mass mobilization; and even when they succeed it is difficult to

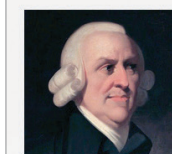

\section{Adam Smith}

$4 \mathrm{hrs} \cdot(3)$

"Whatever praise or blame can be due to any action, must belong either, first, to the intention or affection of the heart, from which it proceeds."

-Adam Smith, The Theory of Moral Sentiments

(1) $0033.4 \mathrm{~K}$

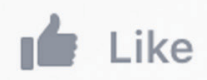

\subsection{K Comments}

\section{Share}

sustain the focus of the protest until it is able to mobilize politicians, institutions, and society at large. As a result, most of these events burst upon the scene, occupy our attention for a few days, and then fade into oblivion with nothing substantial having been accomplished. Given all we have learned about social mobilization, why isn't social media a more reliable channel for constructive social change?

A related observation is that national intelligence agencies are failing to anticipate social uprisings, even when they extensively monitor personal social media networks. Recent global surveillance leaks from Edward Snowden and others show not a single instance where analysis of social media predicted a social uprising or public movement. Social media has been much better at providing the fuel for unpredictable, bursty mobilization than at steady, thoughtful construction of sustainable social change.

Coordinated collective action is a fundamental aspect of all collective intelligence and social decision-making processes. However, despite progress on understanding social mobilization processes we are still a long way from developing a reliable, quantitative theory. In other words, we have developed models able to predict the 
online spread of ideas and news, yet we lack models to predict the behavior change produced by this very same campaign. We argue these failures of use and prediction are not caused by a lack of expertise in data analysis, but by an insufficient focus on the underlying incentive structures - the hidden network of interpersonal motivations that provide the engine for collective decision making and action.

A number of large-scale social mobilization experiments have revealed the important role of incentive structures in realistic, adversarial settings. These planetary-scale experiments include the DARPA Network Challenge to locate 10 weather balloons tethered at random locations all over the continental U.S., which was won by our team using a recursive incentive scheme to recruit an estimated two million searchers within 48 hours; the DARPA Shredder Challenge, in which we recruited over 3,500 individuals to collaboratively assemble real shredded documents; and the most recent U.S. State Department's Tag Challenge, in which we recruited volunteers to locate individuals "at large" in remote cities within 12 hours and won again using the very same incentive scheme. In each challenge, all competing teams had the same type of message (that is, find the balloons, assemble shreds, find the target individuals), and many of them managed to create viral campaigns that reached large populations and created awareness, yet the efficiency of the strategies varied widely and was strongly correlated with the manner in which their incentive design matched the motivations of the participants. Even in the simple task of finding balloons, we saw teams tapping into people's incentives toward personal profit, charity, reciprocity, or entertainment, with varying degrees of success. Some incentive structures posed by competing teams were compatible with the internal incentive structures of the individuals, and could therefore switch them 'on', activating a network cascade of actions, whereas others did not succeed to do so.

We believe incentive networks play an important middle layer between higher-order concepts such as ideologies and culture, and the digital finger-

\section{Why isn"t \\ social media \\ a more reliable \\ channel for \\ constructive social change?}

prints left by social movements in online digital platforms such as Twitter and Facebook. Ideologies and culture shape what individuals want to achieve as they go about their daily life, how they relate to each other's well-being, and how they help each other achieve those goals. This can be mapped into a network of incentives where each individual payoff depends on others individual payoff. Incentives structures are shaped by more abstract underlying processes, but can be mapped quantitatively by these large-scale collective action experiments.

The inability to sustain and transfer bursts of social mobilization in order to create lasting social change is rooted in the design of today's digital social media. Today's social media is designed to maximize information propagation and virality (through optimization of clicks and shares) to the detriment of engagement and consensus building. For instance, Onnela and Reed-Tsochas ${ }^{19}$ demonstrate that even when external signals are absent, digital social influence spontaneously assumes an unstable all-or-nothing nature. The result is "flash fads," the ever-changing inception, competition, and death of new fads that annihilate each other, as they compete for people's attention, with no long-lasting result. ${ }^{31}$ Effective social mobilization is a product of both information diffusion and action recruitment incentives, yet the pressures of the social media business have focused on diffusion to the detriment of incentives for recruiting people to act. Even from the business perspective, social media is extraordinarily ineffective at the goal of recruitment to action, for example, clicking through ads to purchase. The best

\section{Calendar of Events}

April 3-6

ISPD'16: International

Symposium on Physical Design,

Santa Rosa, CA,

Sponsored: ACM/SIG,

Contact: Fung Yu Young,

Email: fyyoung@cse.cuhk.edu.hk

April 4-8

SAC 2016: Symposium on

Applied Computing,

Pisa, Italy,

Sponsored: ACM/SIG

Contact: Sascha Ossowski,

Email: sascha.ossowski@urjc.es

April 11-14

CPS Week '16: Cyber Physical

Systems Week 2016,

Vienna, Austria,

Contact: Radu Grosu,

Email: grosu@cs.sunysb.edu

April 12-14

HSCC'16: $19^{\text {th }}$ International

Conference on Hybrid Systems:

Computation and Control

(part of CPS Week),

Vienna, Austria

Contact: Alessandro Abate,

Email: a.abate@tudelft.nl

April 12-14

ICCPS '16: ACM/IEEE $7^{\text {th }}$

International Conference

on Cyber-Physical Systems

(with CPS Week 2016),

Vienna, Austria,

Contact: Ian Mitchell,

Email: mitchell@cs.ubc.ca

April 12-14

IPSN ' 16 : The $14^{\text {th }}$ International

Conference on Information

Processing in Sensor Networks

(co-located with CPS Week 2016),

Vienna, Austria

Contact: George J. Pappas,

Email: pappasg@seas.upenn.edu

April 18-21

EuroSys ' 16: $11^{\text {th }}$ EuroSys

Conference 2016

London, U.K.,

Sponsored: ACM/SIG,

Contact: Peter R Pietzuch,

Email: prp@doc.ic.ac.uk 
minds of our generation may no longer be thinking about how to make people click ads (as Hammerbacher famously said in 2013), ${ }^{15}$ but they have only progressed to thinking about how to make people click 'share' and 'like'.

The bias of commercial social media toward virality has led most researchers and practitioners studying social movements to focus on the dynamics of information diffusion, with particular focus on conditions that cause viral information propagation. But reliable a priori prediction of which content 'goes viral' does not seem to be within reach. Leading network science scholars like Duncan Watts, ${ }^{30}$ Jon Kleinberg, ${ }^{17}$ and Matthew Jackson ${ }^{12}$ have long argued that viral propagation is highly unpredictable, and that our selective observation of successful campaigns provides us with a false narrative of its underlying causes.

Furthermore, although it is possible to engineer 'viral features' into products $^{2}$ viral propagation usually has more to do with the incentives' underlying message spreading than with the message itself, especially in contested

\section{São Paulo School of Advanced Science on i) \\ Algorithms, Combinatorics and Optimization}

July 18-29, 2016 University of São Paulo, Brazil http://sp-school2016.ime.usp.br

Sponsored by FAPESP, the school will host courses on advanced research topics and is aimed at MSc and PhD students, young researchers, and exceptional undergraduate students. Participants may apply for local expenses and travel grants.

\begin{tabular}{|c|c|c|}
\hline \multicolumn{3}{|c|}{ Lecturers } \\
\hline $\begin{array}{l}\text { R. Kleinberg (Cornell) } \\
\text { A. Kostochka (UIUC) } \\
\text { C.L. Lucchesi (UFMS) } \\
\text { R. Morris (IMPA) } \\
\text { S. Robins (USP) } \\
\text { E. Upfal (Brown) }\end{array}$ & $\begin{array}{l}\text { Y. K } \\
\text { D. K } \\
\text { F.K. } \\
\text { F.M. } \\
\text { L. T } \\
\text { D. V }\end{array}$ & $\begin{array}{l}\text { Kohayakawa (USP) } \\
\text { Král' (Warwick) } \\
\text { Miyazawa (UNICAMP) } \\
\text { I. de Oliveira (USP) } \\
\text { Junçel (Waterloo) } \\
\text { Nilliamson (Cornell) }\end{array}$ \\
\hline \multicolumn{3}{|c|}{ Speakers } \\
\hline $\begin{array}{l}\text { C.C. de Souza (UNICAMP } \\
\text { M. Kiwi (U. Chile) } \\
\text { J.L. Szwarcfiter (UFRJ) }\end{array}$ & & $\begin{array}{l}\text { K. Jansen (Kiel) } \\
\text { B. Reed (McGill) }\end{array}$ \\
\hline DFAP & & TSP \\
\hline
\end{tabular}

domains such as politics. Recruitment of people via content creation has been a craft since its inception, ${ }^{4}$ and it is likely to stay as a craft industry for the foreseeable future, given its dependence on immediate individualized sociocultural context. In contrast, if we shift our efforts toward the mapping of incentives, then we may be able to better determine the suitability of content for recruitment to action and to create lasting social change.

In addition to the bias of commercial social media toward virality, research may overemphasize virality because of two pragmatic considerations. First, equating social mobilization with viral information propagation renders the phenomenon amenable to analysis using tools from epidemiology and public health. ${ }^{9,24}$ However, this epidemiological perspective is only useful in a population with conducive socio-political incentives, that is, a society already "switched on." The second reason behind the emphasis on information virality is a phenomenon we may dub network measurability bias, which refers to the tendency to focus on processes that are easily observable within digital social networks (such as 'likes' and 're-tweets'), while neglecting key latent processes such as the ideological, cultural, and economic incentives of actors. Social media is an amazing new instrument that allows social scientists to measure social information spread in real time, yet is almost totally blind to other relevant factors, ${ }^{33}$ such as framing processes,${ }^{6}$ reflection, ${ }^{5}$ consensus formation, or argumentation processes, ${ }^{23,25}$ which are important in connecting content to sustained motivation.

Much progress has been made in understanding incentives in the economic, social, and political sciences. Hurwicz, Maskin, and Myerson received the 2007 Nobel Prize in Economic Sciences for their development of Mechanism Design, a mathematical toolbox designed to uncover and leverage the true preferences of individuals participating in strategic interactions. In addition, laboratory experiments have recently been able to identify how social structure and dynamics shape incentives via stylized repeated cooperation games such as the Prisoner's Dilemma and Ultimatum Games. ${ }^{21,29}$ These strategic scenarios may well be far from the incentives that move people in the real world, ${ }^{27}$ but they can serve as a first "probe" to experimentally uncover dynamic incentive networks, and provide a complement to large-scale social network experiments geared toward behavioral change. ${ }^{8,14,26}$

Information spreading is key to the formation of collective beliefs, opinions, and attitudes. But incentives play an equally important role. Convincing someone of an idea is one thing. Recruiting them to incur substantial time, effort, and risk toward supporting a cause requires much more. What is needed are new experimental paradigms and observational tools that elicit not only communication dynamics, but also the dynamics of underlying individual, social, and cultural incentives operating in social mobilization processes. Results from these experiments should help us develop a new generation of social media, which can go beyond flash fads and viral memes toward consensual construction of sustained change.

Individuals are not atoms. Without the correct incentive structure, a group of individuals cannot mobilize into a sophisticated problem-solving crowd, let alone change society. This is the tragedy of a completely open and equally connected society: when people discuss social issues online, it is very difficult to reliably quantify the importance of the different issues being raised. Both awareness (how many people care about a certain issue) and persistence (how long do they care about this issue) exhibit heavy-tailed distributions. ${ }^{3,7,16,20}$ This makes it difficult for citizens, including scientists studying the phenomenon, to establish clear thresholds of importance for prioritizing among the myriad of potential issues. Without meaningful thresholds for action, the set of alternative issues end up canceling each other out, leading to 'slacktivism', and leaving military or economic force the only path to change.

Individual and collective attention are finite, and the capacity of media platforms and their algorithms' ability to infer, manipulate, and capture attention seems to improve continuous- 
ly. But without social media that also promotes complex coordination and institution building, in the end nothing is achieved. We need a deeper understanding of how to tap into network incentives, and for activating the right incentives through information filtering and consensus building.

However, unlike message content and social network structure, incentives are far less visible. They manifest themselves through the actions of individuals, and often a particular action comes from multiple incentives. Before we produce a practical theory of social mobilization, we need to develop new ways of measuring, influencing, and modeling incentives in networks, and for interpreting individual action in their light. Our efforts in the large-scale mobilization challenges are only a first small step in that direction.

Adam Smith is considered by many to be the intellectual father of the idea that only observable actions matter: people act in the market, and an invisible hand produces an efficient outcome without knowing the private information and motivations behind people's actions. But in his Theory of Moral Sentiments, Smith made it very clear that a true understanding of social phenomena must incorporate the multitude of psychological and cultural motives. By moving our attention from observable viral processes to modeling their underlying motivational dynamics, we would pay tribute to Smith's nuanced understanding of human nature. And, perhaps, along the way, design the next generation of social media.

\section{References}

1. Alstott, J. et al. Homophily and the speed of social mobilization: The effect of acquired and ascribed traits. PLOS ONE 9, 4 (2014), e95140.

2. Aral, S, and Walker, D. Forget viral marketing-Make the product itself viral. Harvard Business Review (2011), 34-35.

3. Bakshy, E. et al. Everyone's an influencer: Quantifying influence on Twitter. In Proceedings of the Fourth ACM International Conference on Web Search and Data Mining. ACM, 2011.

4. Bartels, R. The History of Marketing Thought. Publishing Horizons, Columbus, $\mathrm{OH}, 1988$

5. Baumer, E.P. et al. Reviewing reflection: On the use of reflection in interactive system design. In Proceeding of the 2014 Conference on Designing Interactive Systems (2014), ACM, 93-102.

6. Benford, R.D. and Snow, D.A. Framing processes and social movements: An overview and assessment. Annual Review of Sociology, (2000), 611-639.

Blumm, N. et al. Dynamics of ranking processes in complex systems. Physical Review Letters 109, 12 (2012), 128701.

8. Bond, R.M. et al. A 61-million-person experiment in social influence and political mobilization. Nature 489, 7415 (2012), 295-298.

9. Braha, D. Global civil unrest: Contagion, selforganization, and prediction. PLOS ONE 7, 10 (2012) e48596.

10. Conover, M.D. et al. The digital evolution of occupy Wall street PLOS ONE 8,5 (2013), e64679.

11. Conover, M.D. et al. The geospatial characteristics of a social movement communication network. PLOS ONE 8 3 (2013), e55957.

12. Golub, B. and Jackson, M.O. Using selection bias to explain the observed structure of Internet diffusions. In Proceedings of the National Academy of Sciences 107, 24 (2010), 10833-10836.

13. González-Bailón, S. et al. The dynamics of protest recruitment through an online network. Scientific Reports 1 (2011)

14. Gutiérrez-Roig, M. et al. Transition from reciprocal cooperation to persistent behaviour in social dilemmas at the end of adolescence. Nature Communications 5 (2014).

15. Hammerbacher, J. Charlie Rose and Jeff Hammerbacher talk Data Science in Healthcare; http://www.cloudera.com/content/cloudera/en/ resources/library/aboutcloudera/jeff-hammerbachercharlie-rose.html

16. Karsai, M. et al. Small but slow world: How network topology and burstiness slow down spreading. Physical Review E 83, 2 (2011), 025102

17. Liben-Nowell, D. and Kleinberg, J. Tracing information flow on a global scale using Internet chain-letter data. In Proceedings of the National Academy of Sciences, 105, 12 (2008), 4633-4638.

18. Naim, M. The End of Power: From Boardrooms to Battlefields and Churches to States, Why Being In Charge Isn't What It Used to Be. Basic Books, 2014.

19. Onnela, J.P. and Reed-Tsochas, F. Spontaneous emergence of social influence in online systems. In Proceedings of the National Academy of Sciences 107 43 (2010), 18375-18380

20. Papadopoulos, F. et al. Popularity versus similarity in growing networks. Nature 489, 7417 (2012), 537-540.

21. Peysakhovich, A. et al. Humans display a cooperative phenotype' that is domain general and temporally stable. Nature Communications 5 (2014).

2. Pickard, G. et al. Time-critical social mobilization Science 334, 6055 (2011), 509-512.

23. Rahwan, I. et al. Laying the foundations for a world wide argument web. Artificial Intelligence 171, 10 (Oct. 2007), 897-921.

24. Rutherford, A. Limits of social mobilization. In Proceedings of the National Academy of Sciences 110, 16 (2013), 6281-6286

25. Schneider, J. et al. A review of argumentation for the social semantic Web. Semantic Web 4, 2 (Feb. 2013), 159-218.

26. Shirado, H. et al. Quality versus quantity of social ties in experimental cooperative networks. Nature Communications 4 (2013)

27. Stefanovitch, $N$ et al. Error and attack tolerance of collective problem solving: The DARPA shredder challenge. EPJ Data Science 3, 13 (2014).

28. Tang, M. et al. Reflecting on the DARPA red balloon challenge. Commun. ACM 54, 4 (Apr. 2011), 78-85.

29. Tsvetkova, M. and Macy, M.W. The social contagion of generosity. PLOS ONE 9, 2 (2014), e87275

30. Watts, D.J. Everything Is Obvious: How Common Sense Fails Us. Random House LLC, 2012.

31. Weng, $L$ et al. Competition among memes in a world with limited attention. Scientific Reports 2 (2012)

32. World Economic Forum (WEF). Outlook on the Global Agenda, 2014: http://reports.weforum.org/outlookglobal-agenda-2015

33. Zuckerman, E. The first Twitter revolution? Foreign Policy 14 (2011)

Manuel Cebrian (manuel cebrian@data61.csiro.au) is Research Group Leader with the Data61 Unit at the Commonwealth Scientific and Industrial Research Organisation (CSIRO), Australia.

Iyad Rahwan (irahwan@mit.edu) is an associate professor of Media Arts and Sciences at the Media Lab, Massachusetts Institute of Technology.

Alex "Sandy" Pentland (pentand@mit.edu) directs the MIT Connection Science and Human Dynamics labs and previously helped create and direct the MIT Media Lab and the Media Lab Asia in India.

Copyright held by authors.

\section{INTERACTIONS}

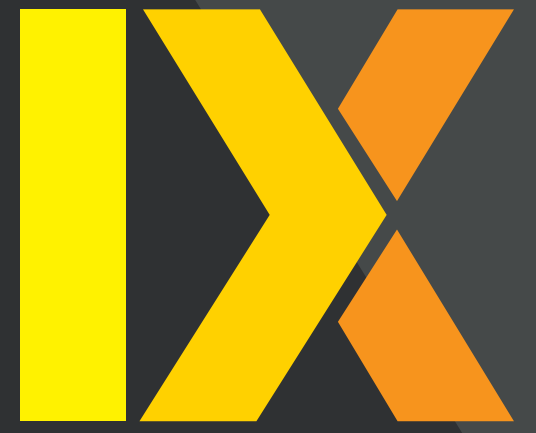

ACM's Interactions magazine explores critical relationships between people and technology, showcasing emerging innovations and industry leaders from around the world across important applications of design thinking and the broadening field of interaction design.

Our readers represent a growing community of practice that is of increasing and vital global importance.

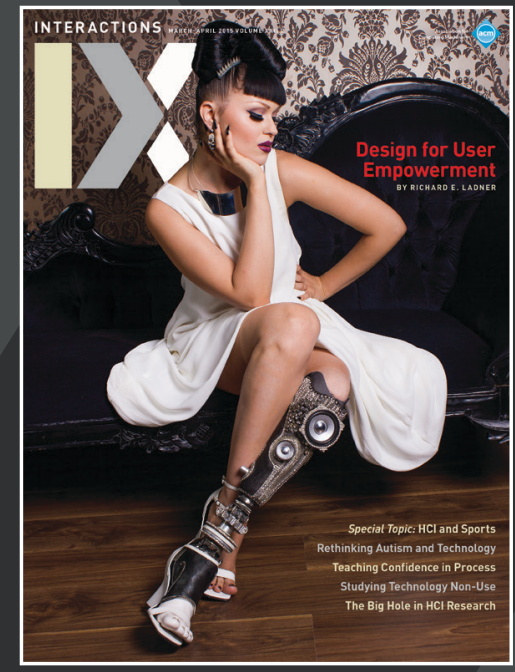

To learn more about us, visit our award-winning website http://interactions.acm.org

Follow us on

Facebook and Twitter

To subscribe:

http://www.acm.org/subscribe

Association for Computing Machinery

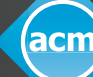

